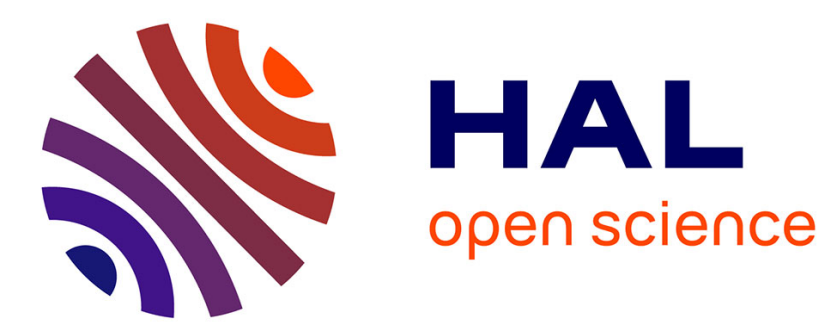

\title{
Infrared Spectroscopy for the Characterization and Quality Control of Moringa Oleifera: a Multivariate Approach
}

Catherine Rébufa, I Pany, Nathalie Dupuy, Isabelle Bombarda

\section{- To cite this version:}

Catherine Rébufa, I Pany, Nathalie Dupuy, Isabelle Bombarda. Infrared Spectroscopy for the Characterization and Quality Control of Moringa Oleifera: a Multivariate Approach. Acta Horticulturae, 2017. hal-01779184

\author{
HAL Id: hal-01779184 \\ https://hal.science/hal-01779184
}

Submitted on 26 Apr 2018

HAL is a multi-disciplinary open access archive for the deposit and dissemination of scientific research documents, whether they are published or not. The documents may come from teaching and research institutions in France or abroad, or from public or private research centers.
L'archive ouverte pluridisciplinaire HAL, est destinée au dépôt et à la diffusion de documents scientifiques de niveau recherche, publiés ou non, émanant des établissements d'enseignement et de recherche français ou étrangers, des laboratoires publics ou privés. 


\title{
Infrared Spectroscopy for the Characterization and Quality Control of Moringa Oleifera : a Multivariate Approach
}

\author{
C. Rébufa, I. Pany, N. Dupuy and I. Bombarda \\ Aix-Marseille Université, LISA EA4672, 13397 Marseille, France
}

Keywords : Moringa oleifera, Chemical composition, Traceability, Spectroscopic techniques, Infrared, Chemometrics, Moisture sorption isotherm.

\begin{abstract}
Moringa oleifera is known for its nutritional and therapeutic potential. This potential is linked to the chemical composition whose variability according to the ecological characteristics and development processes (from harvesting to packaging) can be significant. The influence of parameters such as altitude, weather conditions (temperature, humidity, precipitation), parts of the plant used as well as the influence of the processes for extracting active compounds, the quality of the finished product and/or its maturity level can be apprehended by statistical studies of analytical data. The ultimate goal is to use spectroscopy to ensure the quality control and traceability of different $M$. oleifera samples. Preliminary results on the mineral contents of Moringa plant parts (leaf, stem, bark and flower) show a differentiation depending on the geographical origin (arid zone or wetland). The use of spectroscopic technics associated to chemometric treatments allowed the differentiation of plant parts (leaf, stem and flower) on the basis of their chemical composition and gave informations on the quality of the process (ratio leaf/stem in a powder of dry material or water content for example). Water content of leaves is an important parameter during harvesting, drying, storage or industrial processing for the evaluation and the control of spoilage risks if leaves are used as food commodity. Sorption isotherms of $M$. oleifera leaf powders were used as models to give informations about their humidity equilibrium and their shelf life if they are used as dietary supplement. To achieve our goal, we depend on the validation of a large and representative sampling by local experts.
\end{abstract}

\section{Introduction}

Moringa oleifera is known for its nutritional and therapeutic potential. The plant chemical composition explains for the great part its potential. According to ecological characteristics and depending on the part of the plant considered, this composition could be subject to changes. Other parameters could also influence the chemical content of Moringa oleifera: (i) plant intrinsic characteristics such as its the maturity level of the plant, (ii) environmental conditions to which the plant is exposed such as altitude, weather conditions (temperature, humidity, precipitation), (iii) post-harvest treatments including the development processes (from harvesting to packaging) as well as the laboratory methods used to extract active compounds. They can all impact the quality and the safety 
of all the manufactured goods (tablets and powders sold as dietary supplements) using Moringa oleifera as a raw material. If Leone's publication (2015) provides a synthesis on information available so far concerning the chemical composition of $M$. oleifera leaves from different countries; as for now, few studies have assessed and compared the effect of agroclimatic location on $M$. oleifera phytochemistry. Siddhuraju et al. (2003) examined the radical scavenging capacities and antioxidant activities of aqueous extracts of freezedried leaves of M. oleifera from three different agroclimatic origins. Bennett et al. (2003) investigated the glucosinates as well as flavonoids and chlorogenic acids content of $M$. oleifera leaves from different geographical sources. Iqbal et al. (2006) studied the antioxidant activity of methanolic extract from $M$. oleifera leaves grown in 5 different agroclimatic locations of Pakistan. And finally, Coppin et al. (2013) researched the phenolic content, more particularly the flavonoid content of $M$. oleifera leaves samples collected from two locations. Through all those studies it was found that depending on the geographical distribution of the plant, variations on its leaves'chemical content are observed; none of those studies used infrared spectroscopy and/or chemometric tools to conduct their investigation. Thereby, in this preliminary our goal would be to assess the use of IR spectroscopy coupled with chemometric treatments to not only highlight the geographical origin of different samples of $M$. oleifera but also to ensure their quality control and traceability.

\section{Materials and methods}

Sampling: Moringa oleifera leaves were collected from Burkina Faso (Kongoussi (BF1), Yako (BF2), Garango (BF3), Cameroon (Maroua (CA8 and CA9), Limbé Batoke (CA10), and French Polynesia, Tahiti (PF4 and PF5). Flowers, stems and pods from French Polynesia were also collected. Each sample was then dried at $35^{\circ} \mathrm{C}$ in a ventilated oven for $48 \mathrm{~h}$ and finally reduced into powder before analyses.

Calcium and Iron content: Calcium $(\mathrm{Ca})$ and Iron $(\mathrm{Fe})$ have been analyzed after mineralization in dry oven $\left(550^{\circ} \mathrm{C}, 6\right.$ hours $)$. Ashes have been dissolved with $\mathrm{HNO}_{3}(5 \%$ of the final volume) and ultra pure water. Final dilution of the sample is usually $1 \mathrm{~g} / 50 \mathrm{ml}$ for iron determination, and 1/10000 for $\mathrm{Ca}$ in Moringa leaves. Lanthanum chloride is added to both standards and samples flasks in the $\mathrm{Ca}$ analysis flasks to minimize $\mathrm{Ca}$ ionization in $\mathrm{N}_{2} \mathrm{O}$-Acetylene flame. No modifier is added for Fe determination, in airacetylene flame. The determination is performed with an Agilent 240FS sequential flame atomic spectrometer. Ranges of standards concentrations are $0-10 \mathrm{mg} / \mathrm{l}$ for iron and $0-2.5$ $\mathrm{mg} / \mathrm{l}$ for calcium. The results are given in $\mathrm{mg}$ per $100 \mathrm{~g}$ of sample.

Moisture adsorption isotherms: Moisture adsorption isotherms of Moringa leaves powder were determined by static gravimetric method $\left(\mathrm{g} \mathrm{H}_{2} \mathrm{O} / \mathrm{g}\right.$ dry basis) over a wide range of water activity (from 0.03 to 0.98 ) at room temperature. Approximately, $3 \mathrm{~g}$ of dry sample was placed in a desiccator and exposed to particular relative humidity using salt slurries of potassium chloride. Their activity value was measured at regular intervals 
using an actimeter HygroPalm-HP-23-AW-A (Rotronic) and their moisture content was determined by oven drying at $100^{\circ} \mathrm{C}$ for $48 \mathrm{~h}$.

Near-Infrared (NIR) characterization: NIR spectra were recorded with a Nicolet Antaris II spectrometer interfaced to a computer equipped with Thermo Scientific ${ }^{\mathrm{TM}}$ RESULT software (version 3.6). Powders were analysed by non-destructive diffuse reflection with the help of a micro cup with a quartz window, placed directly on the integrating sphere window. Spectra were recorded between 4000 and $10000 \mathrm{~cm}^{-1}$ with a 4 $\mathrm{cm}^{-1}$ nominal resolution by co-adding 100 scans and using an internal gold reference.

Middle-infrared (MIR) characterization: Powder samples were directly put on the Attenuated Total Reflexion (ATR) accessory (Golden Gate). MIR-ATR spectra were collected at room temperature using a Thermo Nicolet IS10 spectrometer, with a MCT detector. Spectra were acquired between 4000 and $650 \mathrm{~cm}^{-1}$, with a $4 \mathrm{~cm}^{-1}$ nominal resolution. For each spectrum, 100 scans were co-added. Before each sample acquisition, an air background spectrum was acquired. Three spectra were recorded for each sample and were averaged to reduce the possible impact of powder heterogeneity.

Pre-processing of spectral data: For the MIR data, the spectral region between 1900 and $2400 \mathrm{~cm}^{-1}$, corresponding to carbon dioxide absorption, has been removed. Standard Normal Variate (SNV) transformation has been applied on infrared spectral data to remove the major effects of light scattering from spectra by centering and scaling each individual spectrum. Then, a baseline-offset correction was used to correct the baseline of MIR data. Only a baseline correction has been applied on NIR data sets.

Chemometrics treatments: Principal Component Analysis (PCA) and Partial Least Square (PLS) were performed using UNSCRAMBLER software version 10.3 (Computer Aided Modelling, Trondheim, Norway).

\section{Results and discussions}

If used as dietary supplements, Moringa leaves powders could be subjected to moisture content changes that could threaten the microbiological quality and the shelf life of Moringa based products. A solution adopted by manufacturers is the use of sorption isotherms. Indeed sorptions isotherms can be efficiently used to predict moisture changes that may occur during storages and to compare samples moisture content before chemical analyses. In our study, after drying the samples and reducing them into powders, their activity was monitored to control that their moisture content would not impair their preservation (Table 1). Then, for two of those samples: BF1 and CA9, sorption isotherms were established (Fig.1). Equilibrium moisture content is rising with the increase of water activity for both samples. The curves, that may be superimposed, showed sigmoid shape, thus may follow the type II isotherm according to BET classification. Other than the microbiological quality and as $M$. oleifera leaves are increasingly used on programs implemented to fight against malnutrition, it's also important to control their nutritional quality. In this study, we focused on the Calcium $(\mathrm{Ca})$ and Iron $(\mathrm{Fe})$ contents of different parts of the plant (Table 2). Leaves are richer in calcium and iron. Depending on their 
geographic origin (which may take into account parameters such as soil types, cultivation methods), differences in their amount are noticed. Regarding those results, it sounded interesting to see if we could control the geographical origin of our different samples using Infrared (IR) spectroscopy as well as to see if we could detect an impairement of the leave powders by the plant stems. A study of this kind could be of good interest for example to assess the quality of Moringa based manufactured goods and oversee their production process. The spectroscopic techniques followed by multivariate data analysis are well recognized as an potential alternative to the traditional chemical methods in food quality monitoring during the past years. Then, a PCA was performed on MIR data to discriminate samples according to their geographic origin (Fig. 2) and evaluate chemical changes based on the interpretation of changes in position and intensity of characteristic bands. The scores plot in (PC1, PC2) plane of MIR data of Moringa leaves showed that samples could be differentiated according to their geographic origin (Fig. 2a). The PC1 and PC2 components explained respectively $57 \%$ and $23 \%$ of the total variability of the data, according their geogarphic location. The spectral data of CA9, CA10, BF1 and BF3 samples (located in the negative part of PC1 were characterised by spectral bands appearing on the negative part of PC1 loading (Fig. 2b), describing cellulose and other polysaccharides-rich substances such as hemicellulose pectin. As the intensity of these spectral bands was greater, the relative part of these compounds families was more important for these samples. The chemical composition of the other samples appeared abundant in phenolic and aromatic compounds as shown by spectral bands in the positive part of PC1 loading. BF1, BF3 and PF5 samples are grouped together in the positive part of PC2 because of their cutin content whose spectral bands were identified in the positive part of PC2 loading (Fig. 2c). To detect an adulteration of leaves powders by the presence of stems, a PCA was realised on the spectral data currently available. The scores plot (Fig. 3a) suggests that middle infrared spectroscopy data offers the possibility to differentiate the stems and leaves powders. The identified bands in the negative part of PC1 loading (Fig. 3b) showed that esters compounds were more abundant in the stems powder than in leaves powder. A similar separation to the one previously seen on Fig. 2a, between the leaves powders of Burkina Faso, Cameroon and French Polynesia was observed among the PC2 axis which clustured samples according to their relative contents of aromatic or oxygenated compounds. The characteristic spectral bands are pointed in the PC2 loading (Fig. 3c). NIR spectroscopy based on molecular overtone and combination vibrations was used to build PLS models to access moisture content and water activity. Table 3 resumes the performance of the multivariate calibration in terms of the multiple coefficient of determination $\left(\mathrm{R}^{2}\right)$, the standard error of calibration (SEC) or prediction (SEP) and the latent variables (LV). Moisture content showed a higher multiple coefficient of determination than water activity in the calibration model as well in the cross validation. The SEC value was in the same order than the experimental error of the gravimetric determination of moisture content. Here, two latent variables were regressed to predict the studied parameters (Fig. 4). The moisture content is better predicted than water activity value with SEP of 0.058 and $1,46 \%$ respectively. The quality of the fitting 
could be increased with an enrichment of data collection realised on various Moringa samples.

\section{Conclusion}

This preliminary study shows that spectropscopy coupled with chemometric treatments allows to control the quality of Moringa oleifera samples in terms of moisture content (optimization of the shelf-life of products) and chemical composition (selection of a specific plant part). Considering the fact that this investigation was conducted on a low number of samples, the results are promising. In order to efficiently run our studies, we need large and representative $M$. oleifera validated samples from local experts.

\section{Aknowledgments}

Thanks to S. Allard for providing us with samples from Burkina Faso, her nonprofit organization "Fleur de vie" (fleurdevie.over-blog.fr/) and Dr B. Sandjon (Phytorica Laboratory, Cameroon) for his expertise and advices during the sampling process.

\section{Literature Cited}

Bennett, R.N., Mellon, F.A., Foidl, N., Pratt, J.H., Dupont, M.S., Perkins, L. and Kroon, P.A. 2003. Profiling Glucosinolates and Phenolics in Vegetative and Reproductive Tissues of the Multi-Purpose Trees Moringa oleifera L. (Horseradish Tree) and Moringa stenopetala L. J. Agric. Food Chem. 51: 3546-3553.

Coppin, J.P., Xu, Y., Chen, H., Pan, M.-H., Ho, C.-T., Juliani, R., Simon, J.E. and Wu. Q. 2013. Determination of flavonoids by LC/MS and anti-inflammatory activity in Moringa oleifera. Journal of Fonctional Foods. 1892-1899.

Iqbal, S and Bhanger, M.I. Effect of season and production location on antioxidant activity of Moringa oleifera leaves grown in Pakistan. 2006. Journal of Food Composition and Analysis 19: 544-551.

Leone, A., Spada, A., Battezzati, A., Schiraldi, A., Aristil, J. and Bertoli, S. 2015. Cultivation, Genetic, Ethnopharmacology, Phytochemistry and Pharmacology of Moringa oleifera leaves: An Overview. Int. J. Mol. Sci. 16, 12791-12835.

Siddhuraju, P. and Becker, K. 2003. Antioxidant Properties of Various Solvent Extracts of Total Phenolic Constituents from Three Different Agroclimatic Origins of Drumstick Tree (Moringa oleifera Lam.) Leaves. J. Agric. Food Chem., 51, 21442155 


\section{Tables}

Table 1. Water activities (Aw) of Moringa oleifera samples

\begin{tabular}{lllcc}
\hline Country & Sample & Plant Part & Aw & T $\left({ }^{\circ} \mathbf{C}\right)$ \\
\hline Burkina & BF1 & Leaves & 0.393 & 19.7 \\
Faso & BF2 & Leaves & 0.392 & 19.7 \\
& BF3 & Leaves & 0.495 & 20.0 \\
\hline Cameroon & CA8 & Leaves & 0.253 & 18.5 \\
& CA9 & Leaves & 0.236 & 18.9 \\
& CA10 & Leaves & 0.240 & 19.1 \\
\hline French & PF5 & Leaves & 0.506 & 18.9 \\
Polynesia & PF5 & Leaves stems & 0.505 & 18.9 \\
& PF5 & Pods & 0.481 & 19.4 \\
& PF5 & Flowers & 0.474 & 19.1 \\
\hline
\end{tabular}

Table 2. Calcium ( $\mathrm{Ca}$ ) and iron (Fe) content of differents parts of Moringa oleifera

\begin{tabular}{lllcc}
\hline Country & Sample & Plant part & Ca (mg/100g) & Fe (mg/100g) \\
\hline Burkina Faso & BF1 & Leaves & 1893 & 42.1 \\
& BF2 & Leaves & 1920 & 36.3 \\
\hline French Polynesia & PF4 & Leaves & 2772 & 10.1 \\
& PF4 & Leaves stems & 1089 & 3.0 \\
& PF4 & Pods & 139 & 5.8 \\
& PF4 & Flowers & 303 & 7.3 \\
& PF5 & Leaves & 2883 & 15.0 \\
& PF5 & Leaves stems & 1822 & 9.0 \\
& PF5 & Pods & 194 & 7.0 \\
& PF5 & Flowers & 419 & 14 \\
\hline Cameroon & CA8 & Leaves & 1852 & 20.0 \\
& CA9 & Leaves & 1489 & 16.0 \\
& CA10 & Leaves & 1509 & 11.0 \\
\hline
\end{tabular}

Table 3. Parameters of multivariate calibration for quantification of moisture content and water activity of Moringa leaves.

\begin{tabular}{lccccccccc}
\hline & \multicolumn{3}{c}{ Calibration } & & \multicolumn{3}{c}{ Validation } \\
\cline { 2 - 4 } \cline { 8 - 10 } & $\begin{array}{c}\text { Number } \\
\text { of spectra }\end{array}$ & $S E C$ & $R^{2}$ & $L V$ & & $\begin{array}{c}\text { Number } \\
\text { of spectra }\end{array}$ & SEP & $R^{2}$ \\
\hline Water activity & 51 & 0.063 & 0.974 & 2 & & 19 & 0.058 & 0.978 \\
Moisture content & 51 & $1.53 \%$ & 0.993 & 2 & & 19 & $1.46 \%$ & 0.994 \\
\hline
\end{tabular}




\section{Figures}

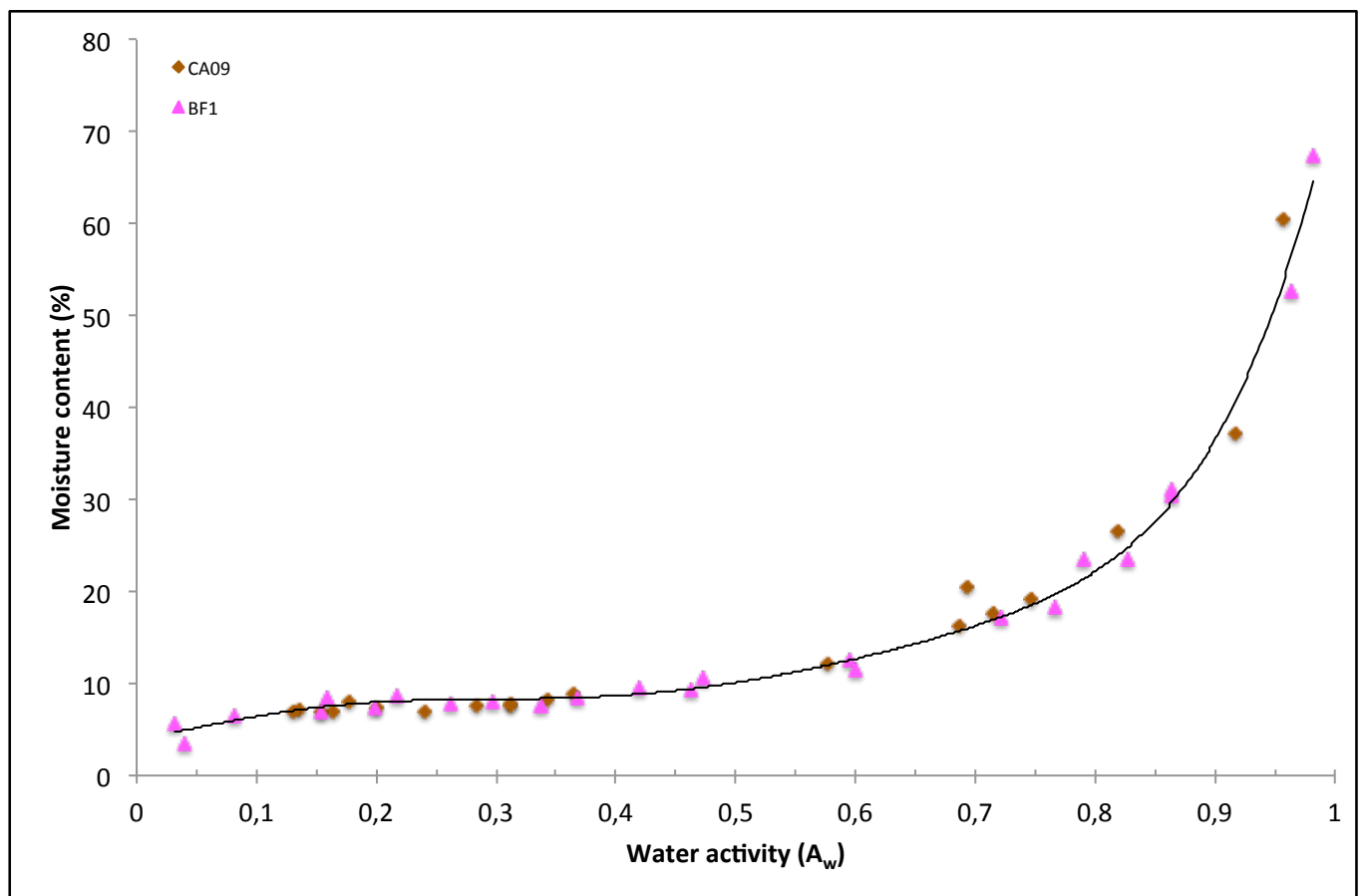

Fig. 1. Sorption isotherms of BF1and CA9 leaves powder.

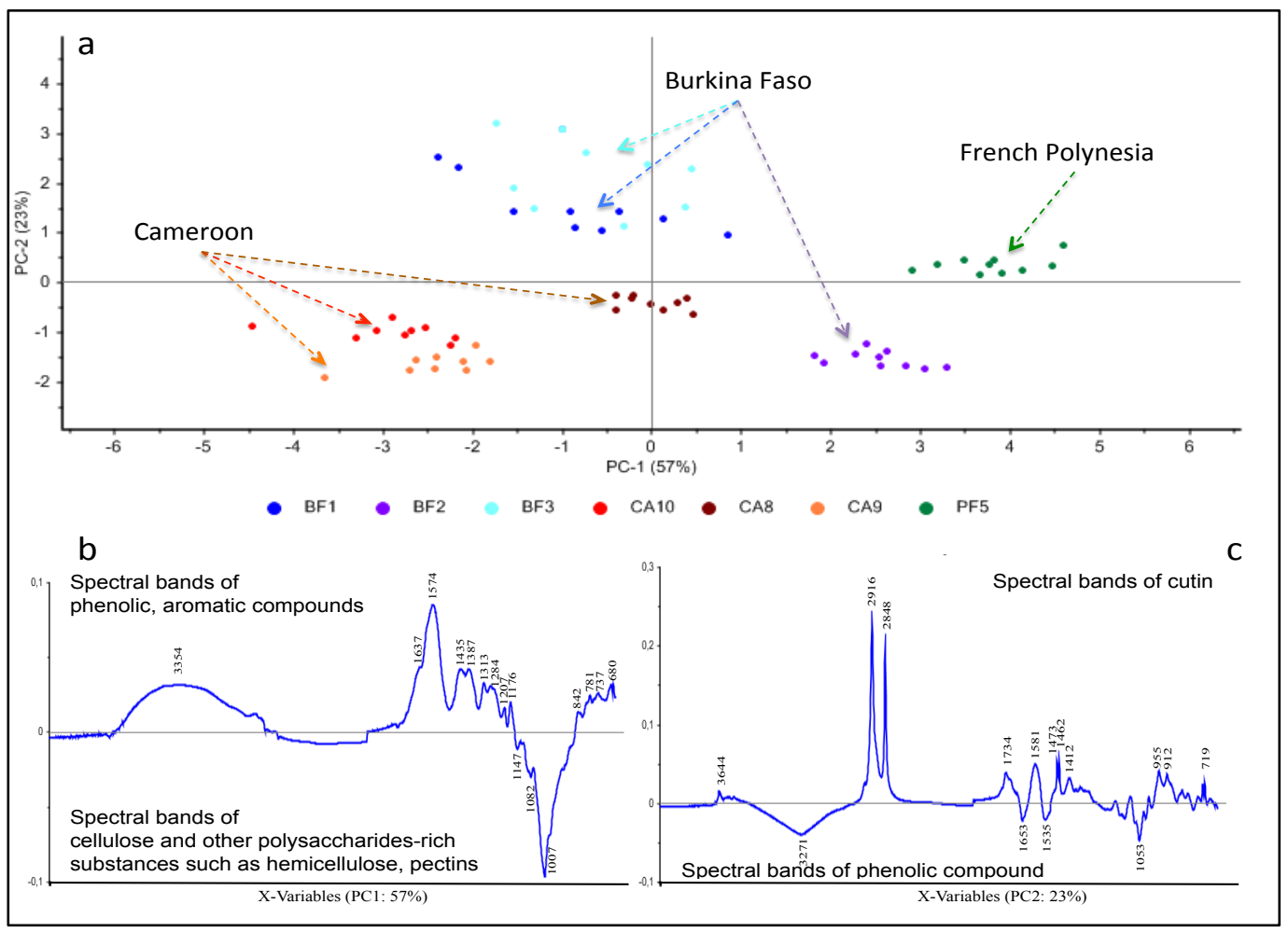

Fig. 2. PCA results on FT-MIR data of leaves: (a) scores plot in (PC1, PC2) plane, (b) PC1 loading, (c) PC2 loading. 


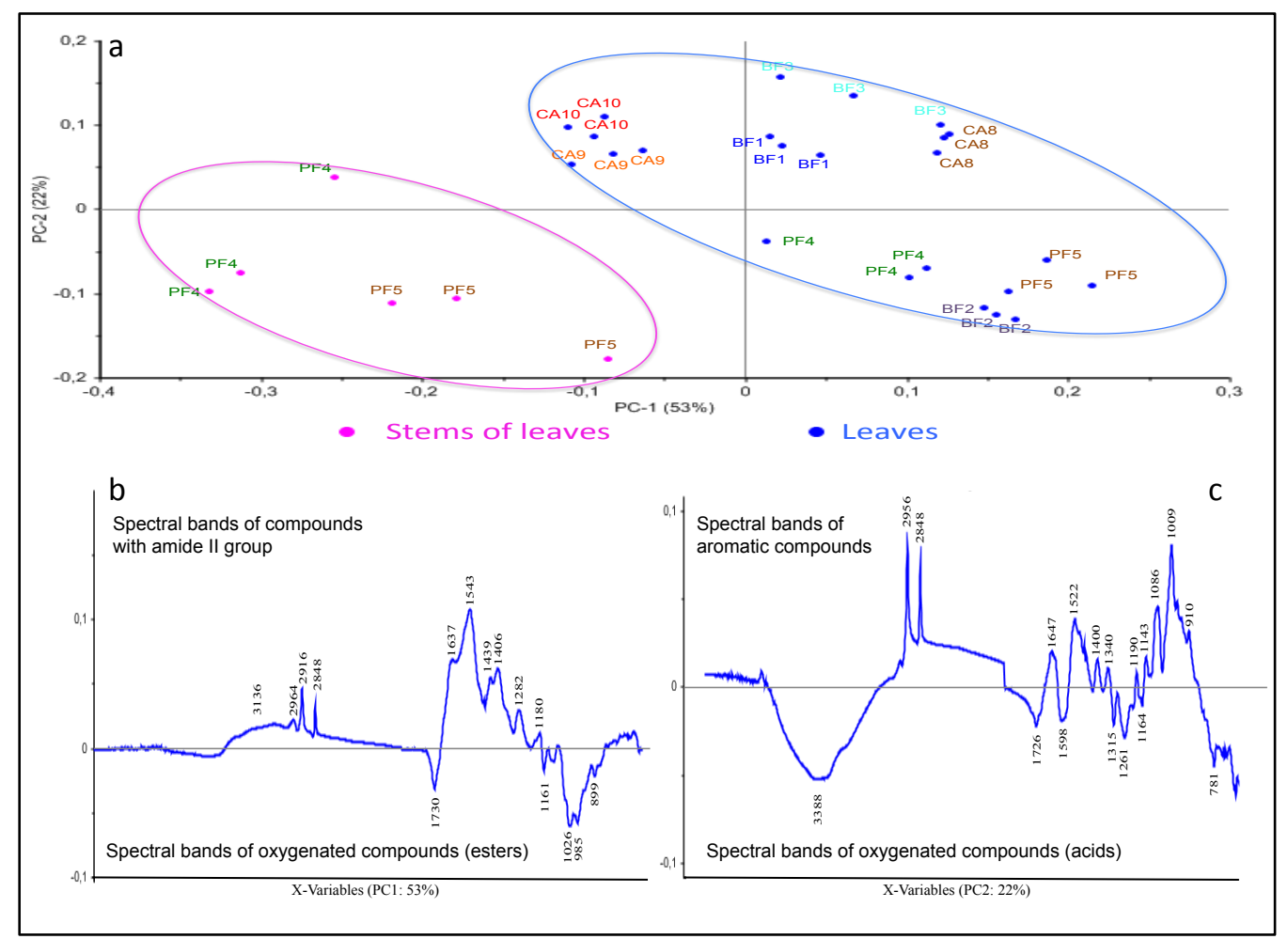

Fig. 3. PCA results on FT-MIR data of leaves and stems: (a) scores plot in (PC1, PC2) plane, (b) PC1 loading, (c) PC2 loading.

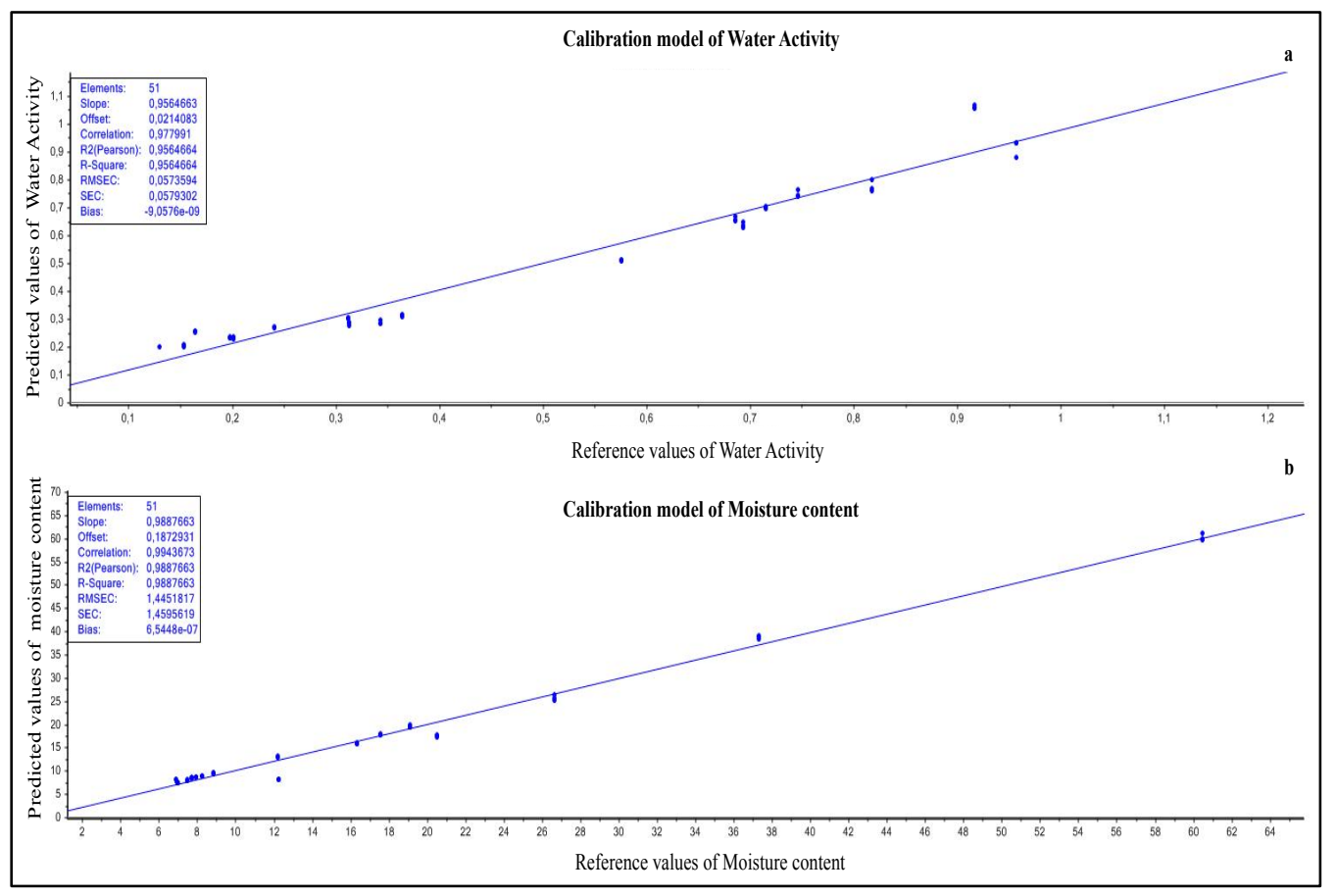

Fig. 4. Plots of predicted versus reference value for calibration model of water activity (a) and moisture content (b). 